\title{
In vitro release studies of furosemide reference tablets: influence of agitation rate, USP apparatus, and dissolution media
}

\author{
Raúl Medina-López *, Sergio Guillén-Moedano and Marcela Hurtado \\ Departamento Sistemas Biológicos, Universidad Autónoma Metropolitana-Xochimilco, Mexico City, Mexico \\ *Corresponding Author: E-mail: rmlopez@correo.xoc.uam.mx; Tel.: + 525554837000 ext. 3445; Fax: + 5255 \\ 55947929
}

Received: March 06, 2020; Revised: June 20, 2020; Published: June 29, 2020

\begin{abstract}
Furosemide is a diuretic drug widely used in chronic renal failure. The drug has low solubility and permeability, which cause clinical problems. Studying the in vitro release performance elucidates the rate and extent of drug dissolved from dosage forms under different conditions. Furosemide reference tablets were tested using USP Apparatuses 1 and 2 as well as the flow-through cell method (USP Apparatus 4), a dissolution apparatus that simulates the human gastrointestinal tract better than the other methods. Dissolution profiles were created with USP Apparatuses 1 and 2 at 25, 50, and $75 \mathrm{rpm}$ and $900 \mathrm{~mL}$ of $0.1 \mathrm{M}$ hydrochloric acid, acetate buffer ( $\mathrm{pH} 4.5)$, and phosphate buffer ( $\mathrm{pH} \mathrm{6.8).} \mathrm{USP} \mathrm{Apparatus} 4$ with a laminar flow of $16 \mathrm{~mL} / \mathrm{min}$ and $22.6 \mathrm{~mm}$ cells was used. Drug dissolution was quantified at $274 \mathrm{~nm}$ for $60 \mathrm{~min}$. Mean dissolution time, dissolution efficiency, time to $50 \%$ dissolution, and time to $80 \%$ dissolution data were used to compare dissolution profiles. Additionally, zero-order, first-order, Higuchi, Hixson-Crowell, Makoid-Banakar, and Weibull models were used to adjust furosemide dissolution data. Between USP Apparatus 1 and 2, significant differences were observed in almost all parameters at 50 and $75 \mathrm{rpm}(\mathrm{p}<$ 0.05). A similar dissolution profile $\left(f_{2}>50\right)$ with a pharmacopoeial dissolution method (USP Apparatus 2 at $50 \mathrm{rpm}$ and $900 \mathrm{~mL}$ of phosphate buffer pH 5.8) and USP Apparatus 4 (laminar flow of $16 \mathrm{~mL} / \mathrm{min}, 22.6 \mathrm{~mm}$ cells, and pH 6.8) was observed. The Weibull function was the best mathematical model to describe the in vitro release performance of furosemide in the three USP dissolution apparatuses. These results could be used to manufacture better furosemide dosage forms and decrease the negative clinical impact of current furosemide formulations.
\end{abstract}

(C)2020 by the authors. This article is an open-access article distributed under the terms and conditions of the Creative Commons Attribution license (http://creativecommons.org/licenses/by/4.0/).

\section{Keywords}

Flow-through cell method; Furosemide; Lasix ${ }^{\circledR}$ drug product; USP basket and paddle apparatus

\section{Introduction}

Furosemide is a diuretic drug widely used in the treatment of oedematous states associated with cardiac, chronic renal failure, hypertension, congestive heart failure, and cirrhosis [1]. Furosemide is a weak acid ( $\mathrm{pKa}=3.8$ ) with low solubility and permeability [2]. According to the Biopharmaceutical Classification System, drugs with these characteristics belong to class IV [3]. The chemical structure of furosemide is shown in Figure 1. 


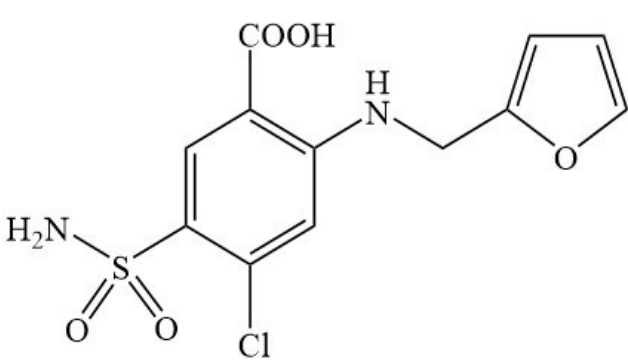

Figure 1. Chemical structure of furosemide.

Factors that affect drug bioavailability related to the pharmaceutical dosage form and manufacturing process have been described [4-5]. Techniques and strategies for the development of class IV drug formulations have also been discussed [6]. This information can support the design of better oral dosage forms of furosemide than those currently available. The oral bioavailability of furosemide has been reported to be $37-51 \%$ [7]

and $60-70 \%$, with a variable and erratic absorption [8]. For the reference product Lasix ${ }^{\circledR}$, an absolute bioavailability of $56 \%$ has been observed [9]. This limited bioavailability could be associated with significant differences in the dissolution behaviour of furosemide commercial formulations shown by several authors. Kaojarern et al. [10] reported an in vitro dissolution study of 13 brands of furosemide tablets (40 $\mathrm{mg}$ ), of which only four fulfil the Q pharmacopoeial specification. Stüber et al. [11] studied the bioavailability of four furosemide drug products, of which three formulations have bioavailabilities of $81-83 \%$ and lower in vitro dissolution performance than the reference in each of following conditions: $\mathrm{pH} 7.8 /$ paddle at $25 \mathrm{rpm}$, $\mathrm{pH} 7.8 /$ paddle at $50 \mathrm{rpm}, \mathrm{pH}$ 5.3/paddle at $50 \mathrm{rpm}$, and flow-through cell $(100 \mathrm{~mL} / \mathrm{h}) / \mathrm{pH} 7.8$. The difference in in vitro dissolution is more pronounced at $\mathrm{pH} 5.3 /$ paddle at $50 \mathrm{rpm}$. Currently, the official dissolution test for furosemide tablets is the USP Apparatus 2 at $50 \mathrm{rpm}$ with $900 \mathrm{~mL}$ of phosphate buffer $\mathrm{pH} 5.8$ and no less than $80 \%$ should be dissolved at $60 \mathrm{~min}$ [12]. A biowaiver monograph has been reported to waiver the in vivo bioequivalence of furosemide solid oral dosage forms by in vitro dissolution studies; however, given the available data, Granero et al. [3] concluded that a biowaiver procedure for this drug cannot be justified.

Low solubility and permeability are problematic characteristics of class IV drugs; thus, the determination of in vitro release performance using different agitation rates, dissolution media, and dissolution apparatuses provides important information for improving the manufacture and evaluation of generic formulations. Despite the wide use of USP basket and paddle apparatuses (USP Apparatus 1 and 2, respectively) to monitor the physical quality of tablets and capsules, several investigations about the hydrodynamic environment that surrounds oral formulations have reported that these USP apparatuses do not adequately reproduce the natural environment of the gastrointestinal tract [13-15]; thus, it is necessary to document the in vitro release performance of poorly soluble drugs under different conditions to establish, in the best possible way, the environment in which the solid dosage forms will be within the gastrointestinal tract. Further, alternative apparatuses must be developed to achieve this goal. The flowthrough cell method (USP Apparatus 4) has been introduced as a dissolution apparatus to elucidate the rate and extent of the dissolution of drugs with low solubility under sink conditions [16]. USP Apparatus 4 is more reliable, reproducible, and discriminative than the other methods [17], and it generates a hydrodynamic environment similar to that inside the gastrointestinal tract [18]. Furthermore, an in vitro/in vivo correlation (IVIVC) has been established between the in vitro data generated with this apparatus and in vivo parameters $[19,20]$.

The aim of this study was to evaluate the in vitro release performance of furosemide reference tablets in the hydrodynamic environments generated by different USP apparatuses and dissolution media of physiological relevance to identify the rate and extent of furosemide dissolution under these conditions. This information will reflect the characteristics of the reference drug product that can be considered in the preparation of a generic formulation. Lasix ${ }^{\circledR}$ tablets were tested with $0.1 \mathrm{M}$ hydrochloric acid, acetate

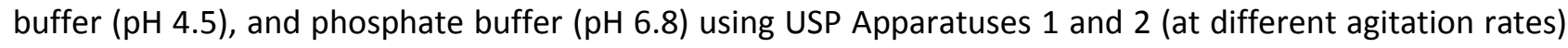
and USP Apparatus 4. 


\section{Experimental}

\section{Materials}

Lasix ${ }^{\circledast}$ furosemide tablets (Sanofi-aventis de Mexico, S.A. de C.V., Mexico City, Mexico) were used. Mexican health authorities have designated this formulation as a reference product to be used in dissolution and bioequivalence studies [21].

\section{Reagents}

Hydrochloric acid, sodium acetate, acetic acid, and phosphate salts were purchased from J.T. BakerMexico (Xalostoc, Mexico). Furosemide reference standard was purchased from Sigma-Aldrich Co. (St. Louis, MO, USA). All samples were filtered through $0.45 \mu \mathrm{m}$ nitrocellulose filters (Millipore, Ireland). Standard solutions were prepared by serial dilutions of the stock solutions of furosemide $(1 \mathrm{mg} / \mathrm{mL})$ to achieve concentrations of $1.25-20 \mu \mathrm{g} / \mathrm{mL}$. The dissolution media comprised $0.1 \mathrm{~N}$ hydrochloric acid, acetate buffer (pH 4.5), and phosphate buffer (pH 6.8).

\section{Content uniformity and assay}

Content uniformity and assay tests were performed with the drug product according to the procedures described in the USP [12].

\section{USP basket and paddle apparatus}

Dissolution profiles of furosemide were obtained using USP Apparatuses 1 and 2 (Model AT-7 Smart, Sotax, Basel, Switzerland) with 25, 50, and $75 \mathrm{rpm}$ agitation rates. Additionally, pharmacopoeial dissolution conditions (USP Apparatus 2 at $50 \mathrm{rpm}$ with phosphate buffer (pH 5.8)) were tested [12]. An ultravioletvisible (UV/Vis) spectrophotometer (Model Lambda 35, Perkin Elmer, USA) with $1 \mathrm{~mm}$ flow cells was used. The equipment was controlled by specific software designed by Sotax. Furosemide tablets were sprinkled on $900 \mathrm{~mL}$ of $0.1 \mathrm{~N}$ hydrochloric acid, acetate buffer $(\mathrm{pH} 4.5)$, and phosphate buffer $(\mathrm{pH} 6.8)$ at $37.0 \pm 0.5$ ${ }^{\circ} \mathrm{C}$. Samples were taken automatically every $5 \mathrm{~min}$ for $60 \mathrm{~min}$. Dissolved furosemide was quantified with standard calibration curves, in each dissolution medium, at $274 \mathrm{~nm}$.

\section{Flow-through cell method}

Dissolution profiles of furosemide were obtained with USP Apparatus 4 (Model CE6, Sotax AG, Basel, Switzerland) with $22.6 \mathrm{~mm}$ cells (i.d.). The laminar flow (originated with $6 \mathrm{~g}$ of glass beads) of $16 \mathrm{~mL} / \mathrm{min}$ was tested. The dissolution media also comprised $0.1 \mathrm{M}$ hydrochloric acid, acetate buffer $(\mathrm{pH} 4.5)$, and phosphate buffer ( $\mathrm{pH} \mathrm{6.8)}$ at $37.0 \pm 0.5^{\circ} \mathrm{C}$. Samples were taken automatically every 5 min for $60 \mathrm{~min}$. Dissolved furosemide was quantified in a UV/Vis spectrophotometer (Model Lambda 10, Perkin Elmer, USA) with $1 \mathrm{~mm}$ cells at $274 \mathrm{~nm}$. For every trial, and depending on the schedule work, a standard calibration curve in $0.1 \mathrm{~N}$ hydrochloric acid, acetate buffer $(\mathrm{pH} 4.5)$ or phosphate buffer $(\mathrm{pH} 6.8)$ was prepared.

\section{Dissolution data analysis}

Dissolution profiles were compared with model-independent and model-dependent approaches. For model-independent comparisons, mean dissolution time (MDT) and dissolution efficiency (DE) were calculated. MDT is the time to dissolve $63.2 \%$ of the drug and was calculated according to the statistical moment's theory [22,23]. Other authors have indicated the MDT to be 62-64 \% [24]. DE is the area under the dissolution curve up to a certain time, $t$, expressed as a percentage of the area of the rectangle described by $100 \%$ dissolution in the same period [25]. Both parameters were calculated with the Excel 
add-in DDSolver program [26].

For model-dependent comparisons, dissolution data were adjusted to a hyperbole equation $(y=a x / b+x)$ and, using $\mathrm{a}$ and $\mathrm{b}$ parameters, time to $50 \%$ dissolution $\left(t_{50 \%}\right)$ and time to $80 \%$ dissolution $\left(t_{80 \%}\right)$ were calculated. The fit was calculated using SigmaPlot software (version 11.0). For a complete comparison of dissolution data by a model-dependent approach, dissolution data were fitted to zero-order, first-order, Higuchi, Hixson-Crowell, Makoid-Banakar, and Weibull models. The model with the highest adjusted determination coefficient ( $R_{\text {adjusted }}^{2}$ ) and lowest Akaike information criterion (AIC) is the best-fit model [27]. Data analysis was carried out using Excel add-in DDSolver program [28]. All statistical comparisons were carried out with Student's t-tests with significant differences at $p<0.05$.

\section{Results}

\section{Content uniformity and assay}

The drug product used met the content uniformity and assay tests specified in the USP. The percentage of furosemide in the content uniformity test ranged from $97.4-100.31 \%$ (pharmacopoeial criteria, 85-115 $\%$ ) and that in the assay test was $100.79 \%$ (criteria, 90-110\%) [12].

\section{Dissolution profiles with USP basket and paddle apparatus}

Dissolution profiles of furosemide obtained with the USP Apparatuses 1 and 2 at different agitation rates and in different dissolution media are shown in Figure 2.

A limited amount of furosemide dissolved in $0.1 \mathrm{M}$ hydrochloric acid at $60 \mathrm{~min}$ with both USP dissolution apparatuses (<20\%). Almost $60 \%$ of the drug dissolved using USP Apparatus 2 at 75 rpm with acetate buffer $(\mathrm{pH} \mathrm{4.5)}$ as the dissolution medium. A complete release of the drug was achieved using phosphate buffer ( $\mathrm{pH} \mathrm{6.8)} \mathrm{at} 50$ and $75 \mathrm{rpm}$, independent of the USP apparatus used. To compare dissolution profiles between USP Apparatuses 1 and 2, model-independent and -dependent parameters, at pH 6.8, were calculated, the results of which are shown in Table 1.

At $25 \mathrm{rpm}$ and with both USP apparatuses, less than $65 \%$ of furosemide dissolved; thus, the $t_{80 \%}$ was not calculated. At this agitation rate, significant differences in MDT values were observed $(p<0.05)$. At $50 \mathrm{rpm}$, significant differences in all calculated parameters were observed $(p<0.05)$. These results suggest a complete non-equivalence in the dissolution performance of furosemide between USP Apparatuses 1 and 2 at these conditions ( $\mathrm{pH} 6.8$ and $50 \mathrm{rpm}$ ). At $75 \mathrm{rpm}$, significant differences in MDT, DE, $t_{50 \%}$, and $t_{80 \%}$ values were observed $(p<0.05)$. Higher values of MDT, $t_{50 \%}$, and $t_{80 \%}$ were observed with USP Apparatus 1 than with USP Apparatus 2, at 50 and $75 \mathrm{rpm}$; these findings could be attributed to slower in vitro dissolution rates in USP Apparatus 1. Dissolution data at $\mathrm{pH}$ 6.8, adjusted with different mathematical models, are shown in Table 2. 


\section{USP Apparatus 1}
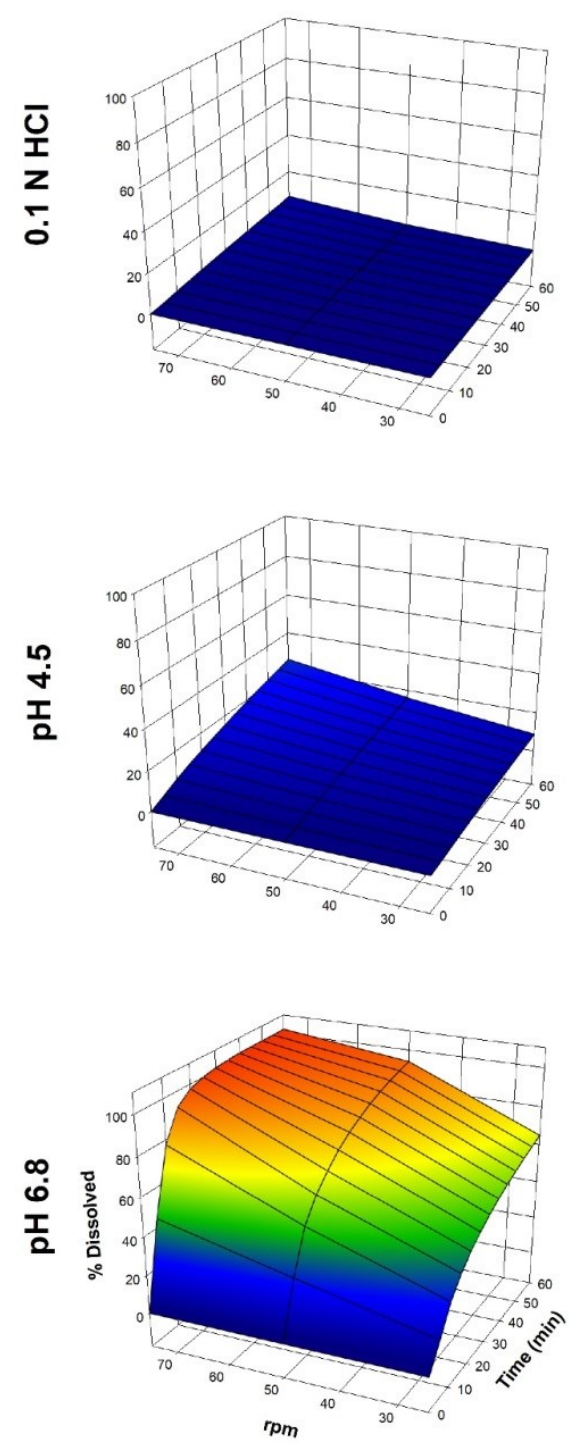

\section{USP Apparatus 2}
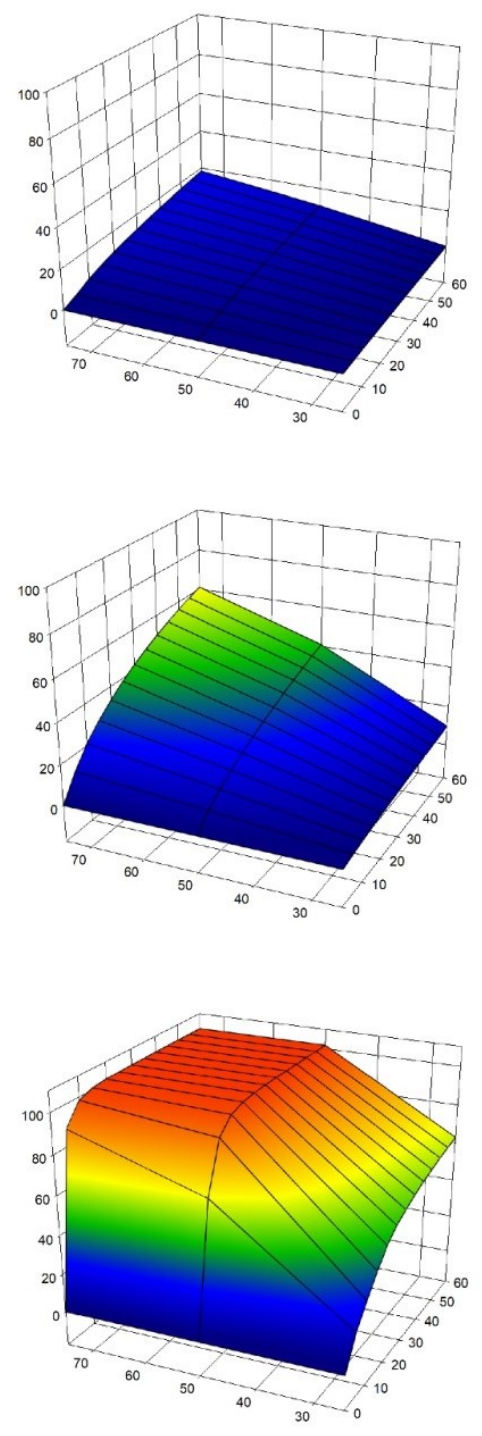

Figure 2. Dissolution profiles of furosemide reference tablets using USP Apparatuses 1 and 2 with dissolution media in physiological $\mathrm{pH}$ range. Mean, $\mathrm{n}=6$.

Table 1. Model-independent and -dependent parameters of furosemide at $\mathrm{pH}$ 6.8. Mean $\pm \mathrm{SEM}, \mathrm{n}=6$.

\begin{tabular}{|c|c|c|c|}
\hline Agitation rate (rpm) & Parameter & USP Apparatus 1 & USP Apparatus 2 \\
\hline & Diss. at $60 \mathrm{~min}(\%)$ & $64.61 \pm 1.64$ & $62.98 \pm 5.87$ \\
\hline & MDT (min) & $18.94 \pm 0.16$ & $17.11 \pm 0.42 *$ \\
\hline \multirow[t]{5}{*}{25} & DE (\%) & $44.42 \pm 1.18$ & $45.15 \pm 4.49$ \\
\hline & $t_{50 \%}(\min )$ & $31.09 \pm 1.89$ & $33.07 \pm 8.47$ \\
\hline & $t_{80 \%}(\min )$ & $\dagger$ & $\dagger$ \\
\hline & Diss. at $60 \mathrm{~min}(\%)$ & $93.90 \pm 2.23$ & $101.76 \pm 0.54^{*}$ \\
\hline & MDT (min) & $15.00 \pm 0.81$ & $4.99 \pm 0.14^{*}$ \\
\hline \multirow[t]{5}{*}{50} & $\mathrm{DE}(\%)$ & $70.56 \pm 2.85$ & $93.30 \pm 0.43^{*}$ \\
\hline & $t_{50 \%}(\min )$ & $11.15 \pm 1.35$ & $2.07 \pm 0.11^{*}$ \\
\hline & $t_{80 \%}(\min )$ & $32.27 \pm 4.02$ & $6.75 \pm 0.30^{*}$ \\
\hline & Diss. at $60 \mathrm{~min}(\%)$ & $102.43 \pm 0.30$ & $102.02 \pm 0.48$ \\
\hline & MDT (min) & $7.49 \pm 0.41$ & $3.42 \pm 0.01 *$ \\
\hline \multirow[t]{3}{*}{75} & $\mathrm{DE}(\%)$ & $89.64 \pm 0.77$ & $96.20 \pm 0.45^{*}$ \\
\hline & $t_{50 \%}(\min )$ & $4.13 \pm 0.30$ & $0.72 \pm 0.02 *$ \\
\hline & $t_{80 \%}(\min )$ & $11.95 \pm 0.75$ & $2.58 \pm 0.08^{*}$ \\
\hline
\end{tabular}

${ }^{* p}<0.05$. +Data not calculated 
Table 2. Criteria used for the selection of the best-fit model at $\mathrm{pH}$ 6.8. Mean, $\mathrm{n}=6$.

\begin{tabular}{|c|c|c|c|c|c|c|c|}
\hline Parameter & $\begin{array}{c}\text { Agitation rate } \\
\text { (rpm) }\end{array}$ & $\begin{array}{l}\text { Zero- } \\
\text { order }\end{array}$ & $\begin{array}{l}\text { First- } \\
\text { order }\end{array}$ & Higuchi & $\begin{array}{l}\text { Hixson- } \\
\text { Crowell }\end{array}$ & $\begin{array}{l}\text { Makoid- } \\
\text { Banakar }\end{array}$ & Weibull \\
\hline \multicolumn{8}{|c|}{ USP Apparatus 1} \\
\hline \multirow{4}{*}{$R_{\text {adjusted }}^{2}$} & 25 & 0.5474 & 0.8935 & 0.9731 & 0.8155 & 0.9938 & 0.9997 \\
\hline & 50 & -0.2118 & 0.9725 & 0.8774 & 0.8929 & 0.9932 & 0.9996 \\
\hline & 75 & -3.99 & 0.9492 & -0.2872 & 0.6144 & 0.9281 & 0.9994 \\
\hline & 25 & 87.76 & 69.95 & 53.49 & 76.81 & 37.07 & 1.85 \\
\hline \multirow[t]{2}{*}{ AIC } & 50 & 104.11 & 56.38 & 74.14 & 74.83 & 42.38 & 8.99 \\
\hline & 75 & 117.66 & 60.73 & 101.10 & 85.25 & 66.30 & 0.64 \\
\hline \multicolumn{8}{|c|}{ USP Apparatus 2} \\
\hline \multirow{4}{*}{$R_{\text {adjusted }}^{2}$} & 25 & 0.3232 & 0.7889 & 0.9521 & 0.6872 & 0.9952 & 0.9976 \\
\hline & 50 & -17.85 & 0.9611 & 0.8774 & -1.85 & 0.9932 & 0.9999 \\
\hline & 75 & -144.29 & 0.7176 & -50.97 & -31.37 & 0.9016 & 0.9998 \\
\hline & 25 & 90.15 & 73.14 & 55.70 & 79.54 & 27.37 & 17.52 \\
\hline \multirow[t]{2}{*}{ AIC } & 50 & 120.96 & 36.84 & 74.14 & 98.05 & 42.38 & -34.36 \\
\hline & 75 & 123.27 & 42.04 & 110.92 & 105.23 & 37.35 & -40.46 \\
\hline
\end{tabular}

Considering the established criteria to choose the best-fit model (higher $R_{\text {adjusted }}^{2}$ and lower AIC values), the Weibull function was the best mathematical equation to describe all dissolution data at $\mathrm{pH}$ 6.8. The expression of this function is as follows [26]:

$$
F=F_{\max }\left[e^{-\frac{(t-T i)^{\beta}}{\alpha}}\right],
$$

where $F$ is the percent of the drug that dissolved vs. $t$ time, $F_{\max }$ is the maximum percent of the drug that dissolved at infinite time, $\alpha$ is the scale factor of the process, $B$ is the shape factor, and $T i$ is a location parameter of time in which the drug begins to dissolve. The furosemide dissolution data of both USP apparatuses adjusted to the Weibull model dissolution profiles were statistically compared with Td values derived from fitting to this equation. The $T_{\mathrm{d}}$ value represents the time interval necessary to dissolve or release $63.2 \%$ of the drug present in the pharmaceutical dosage form [25] and coincides with MDT if the dissolution rate-time curve can be approximated by a monoexponential equation [22]. The mean values of $\alpha, b, T \mathrm{i}, F_{\max }$ and $T_{\mathrm{d}}$ are shown in Table 3. Significant differences were observed in all comparisons $(\mathrm{p}<$ 0.05).

Table 3. Weibull parameters and Td values at $\mathrm{pH}$ 6.8. Mean, $\mathrm{n}=6$.

\begin{tabular}{|c|c|c|c|c|c|}
\hline Agitation rate (rpm) & $\alpha$ & $B$ & $\pi i$ & $F_{\max }$ & $T_{\mathrm{d}} \pm \mathrm{SEM}(\min )$ \\
\hline \multicolumn{6}{|c|}{ USP Apparatus 1} \\
\hline 25 & 10.25 & 0.63 & 3.12 & 95.48 & $50.15 \pm 9.38$ \\
\hline 50 & 5.81 & 0.59 & 2.70 & 111.03 & $22.78 \pm 3.93$ \\
\hline 75 & 13.30 & 1.15 & 0.72 & 102.43 & $7.64 \pm 0.43$ \\
\hline \multicolumn{6}{|c|}{ USP Apparatus 2} \\
\hline 25 & 30.04 & 0.94 & -0.11 & 70.50 & $25.63 \pm 3.51^{*}$ \\
\hline 50 & 2.75 & 0.84 & 1.53 & 101.76 & $4.72 \pm 0.18^{*}$ \\
\hline 75 & 1.87 & 0.77 & -0.39 & 102.03 & $1.80 \pm 0.12^{*}$ \\
\hline
\end{tabular}

${ }^{*} p<0.05$.

Model-dependent comparisons (by comparing $T_{\mathrm{d}}$ values) indicated that USP Apparatuses 1 and 2 at 50 and $75 \mathrm{rpm}$ generated different dissolution profiles. As both USP dissolution apparatuses and agitation rates created different hydrodynamic environments, these results were expected.

Dissolution profiles with flow-through cell method

Dissolution profiles of furosemide reference tablets using USP Apparatus 4 with $0.1 \mathrm{M}$ hydrochloric acid, acetate buffer (pH 4.5), phosphate buffer ( $\mathrm{pH} 6.8$ ), and laminar flow of $16 \mathrm{~mL} / \mathrm{min}$ are shown in Figure 3 . 


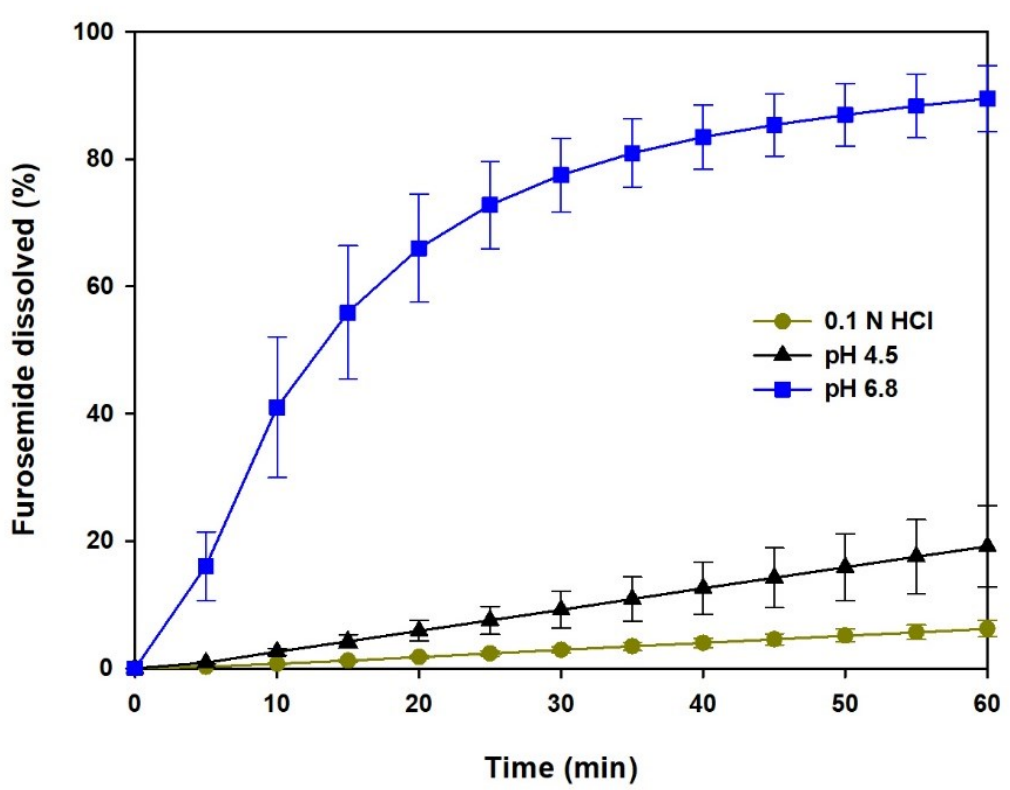

Figure 3. Dissolution profiles of furosemide reference tablets using USP Apparatus 4 with dissolution media in physiological $\mathrm{pH}$ range. Mean $\pm S D, n=12$.

With the flow-through cell method, less than $20 \%$ of furosemide dissolved when $0.1 \mathrm{M}$ hydrochloric acid and acetate buffer ( $\mathrm{pH} 4.5$ ) were used, whereas almost $90 \%$ of the drug was released with phosphate buffer (pH 6.8). Slower dissolution rates with USP Apparatus 4 than with USP Apparatuses 1 and 2 have been found; however, in this case, a dissolution medium with low $\mathrm{pH}$ was an important factor for the low dissolution of furosemide. As more than $80 \%$ of the drug dissolved at $60 \mathrm{~min}$ at $\mathrm{pH} 6.8$ and, for comparative purposes, the dissolution profile of furosemide tablets was obtained using a pharmacopoeial method. A test was carried out with USP Apparatus 2 at $50 \mathrm{rpm}$ with $900 \mathrm{~mL}$ of phosphate buffer (pH 5.8) $(\mathrm{Q}=80 \%$ at $60 \mathrm{~min}$ ), the results of which are shown in Figure 4.

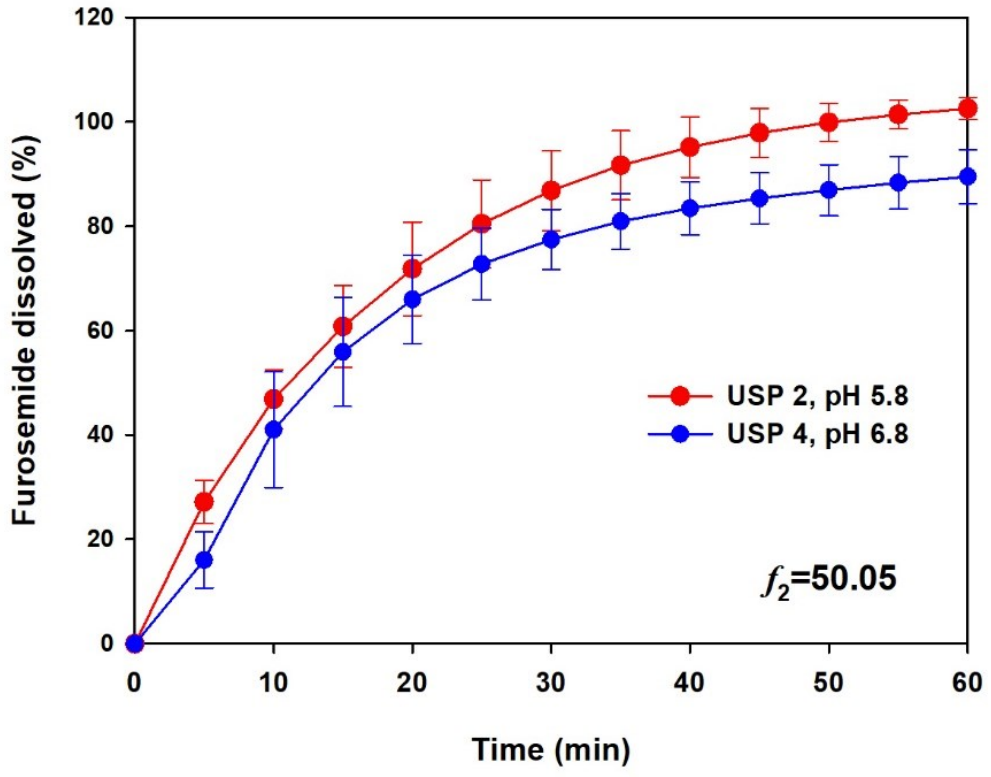

Figure 4. Dissolution profiles of furosemide reference tablets using the pharmacopoeial conditions (USP 2) and flow-through cell method (USP 4) with different dissolution media. Mean $\pm S D, n=12$.

Under official conditions, the furosemide tablets met the Q pharmacopoeial specification ( $>80 \%$ dissolved at $60 \mathrm{~min})$. The dissolution profiles of USP Apparatuses 2 and 4 were $\operatorname{similar}\left(f_{2}>50\right)$. This result suggested that a pharmacopoeial method (USP Apparatus 2) can produce a similar dissolution profile to that obtained with equipment (USP Apparatus 4) that generates a hydrodynamic environment similar to that inside the gastrointestinal tract and for which a correlation with in vivo data has been shown $[19,20]$. For a complete comparison between the profiles, model-independent and-dependent parameters were 
calculated and statistically compared, the results of which are shown in Table 4.

Table 4. Model-independent and -dependent parameters of furosemide. Mean \pm SEM, $n=12$.

\begin{tabular}{|c|c|c|}
\hline Parameter & USP Apparatus 2 (pH 5.8) & USP Apparatus 4 (pH 6.8) \\
\hline Diss. at $60 \mathrm{~min}(\%)$ & $102.55 \pm 0.61$ & $89.49 \pm 1.50^{*}$ \\
\hline MDT (min) & $15.61 \pm 0.68$ & $15.28 \pm 1.06$ \\
\hline DE (\%) & $75.93 \pm 1.52$ & $66.57 \pm 1.44^{*}$ \\
\hline$t_{50 \%}(\min )$ & $10.86 \pm 0.79$ & $13.35 \pm 1.10$ \\
\hline$t_{80 \%}(\min )$ & $25.99 \pm 1.50$ & $36.64 \pm 2.34 *$ \\
\hline
\end{tabular}

Significant differences were observed in percent dissolved at $60 \mathrm{~min}, \mathrm{DE}$, and $t_{80 \%}$ values $(\mathrm{p}<0.05)$, whereas there was no difference in MDT and $t_{50 \%}$, between USP Apparatuses 2 and 4 . If we consider MDT and $t_{50 \%}$ as parameters that reflect the in vitro dissolution rate, this is similar between the conditions (USP Apparatus 2 at $50 \mathrm{rpm}$ and phosphate buffer ( $\mathrm{pH}$ 5.8)/USP Apparatus 4 with a laminar flow of $16 \mathrm{~mL} / \mathrm{min}$ and phosphate buffer ( $\mathrm{pH} 6.8)$ ), at least until the time at which $63.2 \%$ of the drug is dissolved. Furosemide dissolution data obtained with pharmacopoeial conditions and the flow-through cell method, adjusted to mathematical models, are shown in Table 5.

Table 5. Criteria used for the selection of the best-fit model. Mean, $n=12$.

\begin{tabular}{cccccccc}
\hline \multirow{2}{*}{ Parameter } & $\begin{array}{c}\text { USP } \\
\text { Apparatus }\end{array}$ & Zero-order & First-order & Higuchi & $\begin{array}{c}\text { Hixson- } \\
\text { Crowell }\end{array}$ & $\begin{array}{c}\text { Makoid- } \\
\text { Banakar }\end{array}$ & Weibull \\
\hline \multirow{2}{*}{$\mathrm{R}_{\text {adjusted }}^{2}$} & $2(\mathrm{pH} \mathrm{5.8)}$ & 0.1571 & 0.9788 & 0.9152 & 0.9882 & 0.9770 & 0.9994 \\
& $4(\mathrm{pH} \mathrm{6.8)}$ & 0.0115 & 0.9205 & 0.8048 & 0.8488 & 0.9743 & 0.9991 \\
\multirow{2}{*}{ AIC } & $2(\mathrm{pH} \mathrm{5.8)}$ & 104.08 & 58.28 & 75.30 & 52.62 & 30.04 & 8.29 \\
& $4(\mathrm{pH} \mathrm{6.8)}$ & 101.87 & 66.11 & 81.14 & 74.67 & 57.47 & 15.79 \\
\hline
\end{tabular}

The Weibull function was the best-fit model to describe the in vitro release performance of furosemide reference tablets in these two dissolution apparatuses. Weibull parameters and Td values are shown in Table 6. No significant differences were observed in the Td data between the apparatuses $(p>0.05)$.

Table 6. Weibull parameters and Td values. Mean, $\mathrm{n}=12$.

\begin{tabular}{cccccc}
\hline USP Apparatus & $\boldsymbol{\alpha}$ & $\boldsymbol{B}$ & $\boldsymbol{T i}$ & $\boldsymbol{F}_{\max }$ & $\boldsymbol{T}_{\mathrm{d}} \pm \mathbf{S E M}(\mathbf{m i n})$ \\
\hline $2(\mathrm{pH} \mathrm{5.8)}$ & 626.71 & 1.13 & -1.99 & 110.39 & $20.89 \pm 3.93$ \\
$4(\mathrm{pH} \mathrm{6.8)}$ & 12.22 & 0.89 & 3.12 & 92.57 & $16.63 \pm 1.43$ \\
\hline$* \mathrm{p}<0.05$ & & & &
\end{tabular}

The dissolution of furosemide reference tablets using USP Apparatus 4 exceeded the Q pharmacopoeial criterion (only at $\mathrm{pH}$ 6.8) set for certain conditions in the USP Apparatus 2 . When the dissolution data of USP Apparatus 4 were compared with those of USP Apparatus 2 (50 rpm and phosphate buffer pH 5.8), an equivalent in vitro release performance was achieved based on $f_{2}, \mathrm{MDT}, t_{50 \%}$, and $T_{\mathrm{d}}$ comparisons.

Under all conditions used, furosemide dissolution profiles were well described by Weibull function. The shape factor of the Weibull function characterises the dissolution profile as exponential $(\theta=1)$; sigmoidal, with upward curvature followed by a turning point $(\beta>1)$; or parabolic, with steeper initial slope consistent with exponential $(B<1)$ [28]. In this case, furosemide tablets evaluated with USP Apparatus 1 at $75 \mathrm{rpm}$ and $\mathrm{pH}$ 6.8, as well as with USP Apparatus 2 at $50 \mathrm{rpm}$ and $\mathrm{pH}$ 5.8, generated 6 values $>1$, meaning sigmoidal profiles. 


\section{Discussion}

Several authors have studied the effect of the hydrodynamic environment on the tablet dissolution rate. Wu et al. [29] studied the rate process that underlies tablet dissolution to understand the role of external hydrodynamics on mass transfer rate and film thickness during dissolution. Shah et al. [30] stated that the proper medium and appropriate rotational speed of the basket and paddle are of great importance to assure that the test procedure used is useful and discriminatory. Additionally, Levy et al. [31] concluded that the in vitro dissolution rate correlates with the in vivo absorption rate only at a low agitation rate (55 rpm). These results support the search for better dissolution schemes, especially with drugs with poor solubility. Poor permeability is a problem in the design of solid oral dosage forms with good bioavailability; thus, it is important to understand the influence of agitation rate, USP apparatus, and dissolution media on the in vitro release performance of class IV drugs.

The search for adequate dissolution conditions is not limited to poorly soluble drugs or the use of USP Apparatuses 1 and 2. Shabir [32] indicated that the rate of in vitro release of a hydrosoluble drug can be accurately controlled through the USP apparatus. Shabir worked with atenolol (class III drug) generic tablets using USP basket and paddle apparatuses. Although these dissolution apparatuses are currently the most popular methods, Gao [33] explains that both methods are operated under closed finite sink conditions and cannot mimic the conditions in the gastrointestinal tract. The flow-through cell method has gained recent acceptance into the dissolution field for its versatility in the testing of novel dosage forms where traditional dissolution apparatuses and methods have failed [34].

USP Apparatus 4 has several advantages: 1. sink conditions can be maintained for poorly soluble drugs throughout the dissolution run; 2 . it is easy to change media (suggested media is physiological pH range) and modify flow rate to simulate in vivo conditions; 3 . it simulates intraluminal hydrodynamics efficiently; 4. it can be modified for different dosage forms; and 5 . it measures the in vitro release rate profile as an output that is similar to the shape of an in vivo profile [35]. American and European pharmacopoeias suggest three flow rates for testing with USP Apparatus $4(4,8$, and $16 \mathrm{~mL} / \mathrm{min})$ [36]. In this in vitro release study of furosemide reference tablets, we used only the flow rate of $16 \mathrm{~mL} / \mathrm{min}$ as the Sotax equipment model CE6 has a working flow range of $10-50 \mathrm{~mL} / \mathrm{min}$.

Based on these characteristics, it is possible to establish a meaningful IVIVC with USP Apparatus 4. When a meaningful IVIVC has been established, it can be used as a surrogate for and to minimize the number of bioequivalence studies during drug product development [37]. Some authors have reported a better estimate of the absorption rate of cilostazol [19] and diclofenac sodium [20] formulations, both drugs with solubility problems, with the flow-through cell method.

Some drugs can be dissolved using dissolution media in the physiological $\mathrm{pH}$ range $(\mathrm{pH} 1.2,4.5$, and 6.8) or biorelevant media, such as FaSSIF and FeSSIF (media that simulate the absence or presence of food, respectively) [38], to document the release performance of oral dosage forms through the gastrointestinal tract. This is especially important with poorly soluble drugs, such as furosemide. Based on the physicochemical characteristics of this drug, dissolution at low $\mathrm{pH}$ is not physiologically relevant. For a complete dissolution scheme in a physiological $\mathrm{pH}$ range, the Food and Drug Administration recommends dissolution tests with a $0.1 \mathrm{~N}$ hydrochloric acid or simulated gastric fluid USP without enzymes, $\mathrm{pH} 4.5 \mathrm{or} \mathrm{pH}$ 6.8 buffer, or simulated intestinal fluid USP without enzymes [39]. The dissolution of furosemide reference tablets was carried out under these conditions, with the exception of simulated fluids, and the best results were observed with phosphate buffers at pH 5.8 and pH 6.8. More than $80 \%$ of the drug dissolved at 60 min and time parameters, such as MDT, $t_{50 \%}$, and $t_{80 \%}$ were calculated. At $50 \mathrm{rpm}$, significant differences in 
all calculated parameters (USP Apparatus 1 vs. 2) were observed. Differences between both USP apparatuses were expected owing to the different hydrodynamics of each apparatus; however, it is necessary to understand at what agitation rate this difference is more evident. Despite the wide use of USP Apparatuses 1 and 2 at different agitation rates, they have still been evaluated by several authors in terms of the surrounding hydrodynamic environments, which do not adequately reproduce the natural environment of the gastrointestinal tract $[13-15,32,40]$.

The fitting of dissolution data to mathematical models was carried out without any physiological significance to discover the best equation to explain the in vitro release performance of furosemide reference tablets. These models were used to facilitate the analysis and interpretation of dissolution data because they describe the dissolution profiles as a function of the few parameters that can be statistically compared [41]. Han et al. [42] documented the first-order kinetics as the best-fit model to adjust furosemide dissolution data from commercial tablets; however, an incomplete fit scheme was created as only zero-order and first-order kinetics were used to adjust their dissolution data. In our study, after testing several equations (including common dissolution kinetics), Weibull function was the best mathematical model to explain the dissolution performance of furosemide.

The development of more discriminative methods than using pharmacopoeial conditions to evaluate the biopharmaceutical quality of generic formulations has been documented. Studies with class II drugs, such as carbamazepine [43], meloxicam [44], and naproxen sodium [45], tested with USP Apparatuses 2 and 4 have shown that USP Apparatus 2 may not reflect the dissolution performance of generic formulations and references. The choice of the hydrodynamic environment for the drug release is key to identify a meaningful IVIVC [35]. For class II drugs, IVIVCs have been identified and, with in vitro studies, they provide a good estimate of the absorption rate of class II drugs. Several authors have shown this important association only with USP Apparatus $4[19,20,35]$. However, similar dissolution profiles for USP Apparatuses 2 and 4 have been reported for naproxen sodium tablets [45] and ibuprofen suspensions [46]. These results are important where no flow-through cell method is available, and an equivalent hydrodynamic environment is required to test solid dosage forms.

\section{Conclusions}

The in vitro release performance of furosemide reference tablets was determined using USP Apparatuses 1 and 2 at different agitation rates and dissolution media of physiological relevance. A limited amount of furosemide dissolved with both at $\mathrm{pH} 1.2$ and 4.5. Better results were obtained with a dissolution medium of $\mathrm{pH}$ 6.8. Although USP basket and paddle apparatuses are the most widely used, it is important to take advantage of USP Apparatus 4 for the evaluation of furosemide tablets under the hydrodynamic environment that this equipment generates. All information collected is important to reduce the negative clinical impact that this class IV drug presents. This furosemide reference product is the comparative formulation for generic drug products; thus, it is important to understand the in vitro release performance under all possible schemes for the design of better commercial formulations.

Acknowledgements: Authors thanks to QFB Alexander Domínguez Reyes for his technical assistance.

Conflict of interest: Declared None 


\section{References}

[1] H.S. Abou-Auda, M.J. Al-Yamani, A.M. Morad, S.A. Bawazir, S.Z. Khan, K.I. Al-Khamis. Highperformance liquid chromatographic determination of furosemide in plasma and urine and its use in bioavailability studies. Journal of Chromatography B 710 (1998) 121-128.

[2] A. Berthod. Hydrophobicity of ionizable compounds. A theoretical study and measurements of diuretic octanol-water partition coefficients by countercurrent chromatography. Analytical Chemistry 71 (1999) 879-888.

[3] G.E. Granero, M.R. Longhi, M.J. Mora, H.E. Junginger, K.K. Midha, V.P. Shah, S. Stavchansky, J.B. Dressman, D.M. Barends. Biowaiver monographs for immediate-release solid oral dosage forms: furosemide. Journal of Pharmaceutical Sciences 99 (2010) 2544-2556.

[4] G. Tambosi, P.F. Coelho, L. Soares, I.C. Schmücker Lenschow, M. Zétola, H.K. Stulzer, B. Ramos Pezzini. Challenges to improve the biopharmaceutical properties of poorly water-soluble drugs and the application of the solid dispersion technology. Revista Matéria 23 (2018) e-12224.

[5] A. García-Arieta. Interactions between active pharmaceutical ingredients and excipients affecting bioavailability: impact on bioequivalence. European Journal of Pharmaceutical Sciences 65 (2014) 89-97.

[6] R. Ghadi, N. Dand. BCS class IV drugs: highly notorious candidates for formulation development. Journal of Controlled Release 248 (2017) 71-95.

[7] M.R. Kelly, R.E. Cutler, A.W. Forrey, B.M. Kimpel. Pharmacokinetics of orally administered furosemide. Clinical Pharmacology and Therapeutics 15 (1973) 178-186.

[8] S. Sweetman. Martindale: The complete drug reference. (Electronic version) Pharmaceutical Press. Thomson/MICROMEDEX, London, UK/Greenwood Village, Colorado. 2009.

[9] A. Grahnén, M. Hammarlund, T. Lundqvist. Implications of intraindividual variability in bioavailability studies of furosemide. European Journal of Clinical Pharmacology 27 (1984) 595-602.

[10] S. Kaojarern, O. Poobrasert, A. Utiswannakul, U. Kositchaiwat. Bioavailability and pharmacokinetics of furosemide marketed in Thailand. Journal of the Medical Association of Thailand 73 (1990) 191-197.

[11] W. Stüber, E. Mutschler, D. Steinbach. The pharmaceutical and biological availability of commercial preparations of furosemide. Arzneimittelforschung Drug Research 32 (1982) 693-697.

[12] United States Pharmacopeia and National Formulary USP 42-NF 37; United States Pharmacopeial Convention, Inc: Rockville MD; 2019.

[13] M. Morihara, N. Aoyagi, N. Kaniwa, N. Katori, S. Kojim. Hydrodynamic flows around tablets in different pharmacopeial dissolution tests. Drug Development and Industrial Pharmacy 28 (2002) 655-662.

[14] K. Greco, T.L. Bergman, R. Bogner. Design and characterization of laminar flow-through dissolution apparatus: comparison of hydrodynamic conditions to those of common dissolution techniques. Pharmaceutical Development and Technology 16 (2011) 75-87.

[15] V. Todaro, T. Persoons, G. Grove, M.A. Healy, D.M. D'Arcy. Characterization and simulation of hydrodynamics in the paddle, basket and flow-through dissolution testing apparatuses - a review. Dissolution Technologies 24 (2017) 24-36.

[16] S.N. Bhattachar, J.A. Wesley, A. Fioritto, P.J. Martin, S.R. Babu. Dissolution testing of a poorly soluble compound using the flow-through cell dissolution apparatus. International Journal of Pharmaceutics 236 (2002) 135-143.

[17] E. Beyssac, J. Lavigne. Dissolution study of active pharmaceutical ingredients using the flow through apparatus USP 4. Dissolution Technologies 12 (2005) 23-25.

[18] N. Fotaki, C. Reppas. The flow through cell methodology in the evaluation of intralumenal drug release characteristics. Dissolution Technologies 12 (2005) 17-21. 
[19] J. Jinno, N. Kamada, M. Miyake, K. Yamada, T. Mukai, M. Odomi, H. Toguchi, G.G. Liversidge, K. Higaki, T. Kimura. In vitro-in vivo correlation for wet-milled tablet of poorly water-soluble cilostazol. Journal of Controlled Release 130 (2008) 29-37.

[20] E. Jantratid, V. De Maio, E. Ronda, V. Mattavelli, M. Vertzoni, J.B. Dressman. Application of biorelevant dissolution tests to the prediction of in vivo performance of diclofenac sodium from an oral modified-release pellet dosage form. European Journal of Pharmaceutical Sciences 37 (2009) 434-441.

[21] Listado Actualizado de medicamentos de referencia 2019/01, https://www.gob.mx/cms/uploads/attachment/file/441323/Listado de medicamentos de Referencia .pdf, accessed on 04 March 2020.

[22] Y. Tanigawara, K. Yamaoka, T. Nakagawa, T. Unzo. New method for the evaluation of in vitro dissolution time and disintegration time. Chemical and Pharmaceutical Bulletin 30 (1982) 10881090.

[23] P.S. Collier. The interpretation of in vivo mean dissolution time data. In: Benet L.Z., Levy G., Ferraiolo B.L. (eds) Pharmacokinetics. Springer-Verlang. Boston, USA. 1984.

[24] F. Podczeck. Comparison of in vitro dissolution profiles by calculating mean dissolution time (MDT) or mean residence time (MRT). International Journal of Pharmaceutics 97 (1993) 93-100.

[25] P. Costa, J.M. Sousa Lobo. Modeling and comparison of dissolution profiles. European Journal of Pharmaceutical Sciences 13 (2001) 123-133.

[26] Y. Zhang, M. Huo, J. Zhou, A. Zou, W. Li, C. Yao, S. Xie. DD Solver: an add-in program for modeling and comparison of drug dissolution profiles. The AAPS Journal 12 (2010) 263-271.

[27] N. Yuksel, A.E. Kanik, T. Baykara. Comparison of in vitro dissolution profiles by ANOVA-based, model-dependent and independent-methods. International Journal of Pharmaceutics 209 (2000) 57-67.

[28] F. Langenbucher. Linearization of dissolution curves by the Weibull distribution. Journal of Pharmacy and Pharmacology 24 (1972) 979-981.

[29] Y. Wu, D.O. Kildsing, E.S. Ghaly. Effect of hydrodynamic environment on tablet dissolution rate. Pharmaceutical Development and Technology 9 (2004) 25-37.

[30] V.P. Shah, M. Gurbarg, A. Noory, S. Dighe, J.P. Skelly. Influence of higher rates of agitation on release patterns of immediate-release drug products. Journal of Pharmaceutical Sciences 81 (1992) 500-503.

[31] G. Levy, B.A. Hayes. Physicochemical basis of the buffered acetylsalicylic acid controversy. New England Journal of Medicine 262 (1960) 1053-1058.

[32] G.A. Shabir. Evaluation of USP basket and paddle dissolution methods using different generic atenolol tablets. Turkish Journal of Pharmaceutical Sciences 8 (2011) 253-260.

[33] Z. Gao. In vitro dissolution testing with flow-through method: a technical note. AAPS PharmSciTech 10 (2009) 1401-1405.

[34] I. Singh, H.Y. Aboul-Eneim. Advantages of USP Apparatus IV (flow-through cell apparatus) in dissolution studies. Journal of the Iranian Chemical Society 3 (2006) 220-222.

[35] J.B. Fang, V.K. Robertson, A. Rawat, T. Flick, Z.J. Tang, N.S. Cauchon, J.S. McElvain. Development and application of a biorelevant dissolution method using USP Apparatus 4 in early phase formulation development. Molecular Pharmaceutics 7 (2010) 1466-1477.

[36] B. Steffansen, B. Brodin, C. Und Nielsen. Molecular biopharmaceutics: aspects of drug characterization, drug delivery and dosage form evaluation. ULLA Pharmacy Series. Pharmaceutical Press. London, United Kingdom. 2009.

[37] C. Larsen, S.W. Larsen, H. Jensen, A. Yaghmur, J. Østergaard. Role of in vitro release models in formulation development and quality control of parenteral depots. Expert Opinion on Drug Delivery 6 (2009) 1283-1295. 
[38] J.H. Fagerberg, O. Tsinman, N. Sun, K. Tsinman, A. Avdeef, C.A.S. Bergström. Dissolution rate and apparent solubility of poorly soluble drugs in biorelevant dissolution media. Molecular Pharmaceutics 7 (2010) 1419-1430.

[39] US DHHS, FDA, CDER, Guidance for Industry: Waiver if in vivo bioavailability and bioequivalence studies for immediate-release solid oral dosage forms based on a Biopharmaceutics Classification System, U.S. Department of Health and Human Services, Food and Drug Administration, Center for Drug Evaluation and Research (CDER) (2017), Rockville, MD, USA.

[40] S. Missaghi, R. Fassihi. Release characterization of dimenhydrinate from an eroding and swelling matrix: selection of appropriate dissolution apparatus. International Journal of Pharmaceutics $\mathbf{2 9}$ (2005) 35-42.

[41] E. Adams, D. Coomans, J. Smeyers-Verbeke, D.L. Massart. Non-linear mixed effects models for the evaluation of dissolution profiles. International Journal of Pharmaceutics 240 (2002) 37-53.

[42] Y.K. Han, L.D. Simionato, R.G. Calvo, M.B. Mattei, A.I. Segall. Comparison of dissolution profiles of furosemide tablets available in the Argentinian market. Journal of Applied Solution Chemistry and Modeling 3 (2014) 186-193.

[43] J.R. Medina, D.K. Salazar, M. Hurtado, A.R. Cortés, A.M. Domínguez-Ramírez. Comparative in vitro dissolution study of carbamazepine immediate-release products using the USP paddles method and the flow-through cell system. Saudi Pharmaceutical Journal 22 (2014) 141-147.

[44] J.R. Medina-López, J.A. Orozco-Juárez, M. Hurtado. Dissolution performance of meloxicam formulations under hydrodynamics of USP paddle apparatus and flow-through cell method. International Journal of Applied Pharmaceutics 11 (2019) 182-188.

[45] J.R. Medina, A. Uribe, M. Hurtado, A.M. Domínguez-Ramírez. In vitro equivalence study of generic naproxen tablets using the USP paddle apparatus and the flow-through cell method. International Journal of Pharmacy and Pharmaceutical Sciences 7 (2015) 348-354.

[46] J.R. Medina, M. Cortes, E. Romo. Comparison of the USP Apparatus 2 and 4 for testing the in vitro release performance of ibuprofen generic suspension. International Journal of Applied Pharmaceutics 9 (2017) 90-95. 